\title{
Como vueltos a nacer: Diario personal del terremoto en EI Salvador
}

\section{Treinta y dos segundos de zozobra}

- Ricardo Ribero

"Paren esto un momento, que quiero hajarme". Se me viene esa vieja broma bajo el agua de la ducha al momento de sentir las primeras sacudidas. Este planeta se ha vuelto demasiado peligroso, - lo he dicho otras veces recordando esa frase -, habría que buscar algo menos inseguro que esta esfera achatada flotando en la nada. La incipiente sonrisa se me borra cuando a los segundos viene el primer remezón fuerte. No sé con qué mano me enrollo una toalla, ni con qué mano me aferro al muro. Absurdamente, porque esta pared, al igual que el resto de la casa, se mueve como zarandeada por un gigante. Salto hacia la escalera mientras detrás de mí las libreras se vuelcan, el televisor cae y se derrumba parte del cielo falso. De la planta baja llegan gritos mezclados con el estrépito general: ipapi, bajá, que está temblando!

Gracias, ya me habia dado cuenta, pienso... pero no tiene gracia, esto es más grave que un simple temblor. Y me ha pillado desnudo. Como había soñado en mis pesadillas, viene el terremoto y yo, en cueros. La desnudez aumenta mi sensación de impotencia y de total precariedad, el pudor ancestral unido a todos los terrores primigenios. La mente disparada a mil por hora mientras los pies tratan de atinar en los peldaños, de tres en tres, de cuatro en cuatro tal vez. Por un instante me parece revivir experiencias pasadas, el barco estremecido por la tormenta, repentinamente a merced de furiosas olas, el agua en la cara, el viento y el olor a mar mientras trato 
de abandonar la cubierta, deslizarme por la mojada escalerilla y no precipitarme fuera donde el océano furibundo me hubiera engullido en un santiamén. Una tremenda ola ha movido toda la esiructura, me saca de balance y me golpeo una rodilla con el soporte del pasamanos. Chorreo agua y estoy a punto de deslizarme en la última grada. Toda la casa parece ahora a punto de zozobrar. Cruje su quilla mientras allá en la proa, bajo el dintel de la entrada, mi mujer y mi hijo me gritan algo angustiosamente.

Vuelo a grandes zancadas cruzando la sala en mitad del zafarrancho. En el aire trato de decidir dónde pondré el pie. Todo tipo de objetos están regados por el piso. Fragmentos de cerámica, libros, vidrios y pedazos de cosas alfombran el suelo. Milagrosamente paso entre todo ello sin herirme. Aterrizo entre los míos, en esos pocos centímetros cuadrados bajo el dintel que constituyen nuestro único refugio. Alrededor es el caos, mucho peor que cuando entraron los ladrones y hallamos todo botado y revuelto. No nos atrevemos a cruzar el garaje para ganar la calle. Las tejas amenazan desplomarse; parece más seguro el marco de la puerta. El vehículo está brincando a cada sacudida, como si hubiera entrado en orgasmo. Me recuerda la escena de la pareja haciendo el amor en un viejo automóvil en la panza del Titanic y me entra una risa nerviosa. Ya va a pasar, nos repite tranquilizadora mi mujer. Pero tarda en calmarse. Qué eternos se hacen estos segundos. Dios, ¡qué insignificantes y poca cosa somos en realidad!

Cesa por fin el ruido de cosas cayendo y quebrándose, el crujido doliente de muros y techos, el ronco rugido que sube de lo hondo de la tierra. La casa parece recobrar ahora su acostumbrada solidez. La miro con sorprendida gratitud. Unos segundos antes tuve la seguridad de que iba a derrumbarse, que no era posible la pasmosa elasticidad de hule, el ondular increíble de toda la construcción. Vaya, parece que estos ingenieros saben lo que hacen. Nos miramos los tres con ojos de náufrago. ¡Nuevamente tierra firme!

\section{Las horas posteriores}

Subo a buscar mi ropa. El agua sigue manando de la ducha, en mudo testimonio de mi pánico anterior, cuando huí despavorido. La cierro ahora, ignorante de que durante más de 24 horas estaremos sin agua. El dormitorio de la planta alta ha quedado peor que abajo. Un ladrillo dejado por la constructora sobre una plancha del cielo falso ha caído junto con ella, dejando una fea mancha en el cubrecama. Si el temblor hubiera sido en la noche nos cae encima, pienso, maldiciendo en mi interior al irresponsable. El cadáver del televisor yace a un lado y me le acerco cauteloso. Ha caído de cara, empujado por una librera derribada. No es posible, pienso, que no haya estallado la pantalla. Pero ahí está el milagro: una pequeña muñeca plástica, recuerdo de infancia de mi hija, se deslizó a tiempo entre el aparato y el piso, salvándole la vida al veterano artefacto. Días después mi esposa descubrirá que sigue funcionando, como si nada. Otro superviviente. 
Pero, ¿qué hacen dentro de la casa? - nos increpa nuestra hija que va llegando-, todo el mundo está en la calle. Parece tan animosa en este momento, tan dueña de sí, que me deja admirado. Después estallará en llanto, desahogándose, mientras nos cuenta cómo Hugo, su buen amigo de la vecindad, no le_permitió que se arriesgase escaleras abajo en mitad del repentino vaivén. Su hermano reacciona distinto, con excitación evidente, al comprobar que esto que acaba de vivir es un terremoto, mi primer terremoto, repite. Salimos, no sin antes cerrar la válvula del tambo de gas, no vaya a ser que repita el temblor y se produzca un escape.

El pasaje bulle de vecinos. Tejas caídas, grietas, alguna pared rajada, una porción de la acera levantada... nada serio. Las primeras llamadas telefónicas con los amigos aпrojan la misma impresión: un gran susto, pero sin consecuencias dramáticas. Imposible buscar noticias por televisión, se cortó la luz. Un vecino ha puesto la radio del carro y todos nos acercamos a escuchar los primeros avances. Los de la KL, los mismos héroes de los reportajes de guerra, se han lanzado a cubrir el evento. Informan de un desprendimiento de lodo y rocas. Por tal motivo, la carretera a Santa Ana ha quedado cortada, a la altura de Los Chorros. Una señora y sus dos hijas murieron ahí. De momento sólo se conoce de estas tres víctimas mortales. Después sabré por Carlos de lo grave que fue el deslave en ese lugar: su cuñada casi muere soterrada. Ella y una prima tuvieron que salir del bus por una ventana y escapar con lodo hasta la cintura, entre la histeria y los gritos de la gente, mientras otros fueron aplastados o arrastrados por la correntada. Curiosamente en los primeros minutos las noticias son más bien tranquilizadoras. Sin embargo, tengo un mal presagio. El país me parece tan frágil, hay tanta pobreza, tanta vivienda precaria... iy tanto pillo haciendo negocio con la necesidad de la gente!

Decidimos visitar a Celsa, la mamá de Claudia, la amiga de mi hija. Su casa no queda lejos. Es en esa colonia, construida en parte sobre malerial de relleno, donde una hilera entera de viviendas se hundió con las primeras lluvias del invierno pasado. Llegamos y observamos con alivio que todo sigue en pie, incluidas las casas condenadas al derribo, agrietadas y medio ladeadas por culpa de otro constructor irresponsable. La puerla de la vivienda está abierla de par en par y adentro no se mira mayor desorden, pero no están Celsá ni los niños. Salió donde su mamá, nos informa un vecino. Dudo si cerrar o no la casa, no vaya a ser que se haya ido sin las llaves. Se puede ir confiado - me tranquiliza el mismo señor de antes- aqui cuidamos entre lodos de que no le roben a la vecina. Es sólo un pequeño gesto de solidaridad, pero reconforta. Regresamos aliviados.

Otros amigos de la colonia van llegando ahora, con el rostro sombrio. Nosotros venimos de Santa Tecla; ahi se ha caido un montón de casas, - nos cuentan doña Carmen y su esposo- las de adobe y las de bahareque no han resisti-

Como vuelitos a nacer: Diario personal del terremoto 
do; el centro de la ciudad está lleno de escombros. Me sorprende, pues siempre había escuchado sobre las cualidades antisísmicas del bahareque, sobre la flexibilidad que adquiere el lodo mezclado con un entramado de cañas y vara de Castilla, según una técnica indígena precolombina. Más tarde comprobaré la falsedad de dichas creencias, pues en la UCA hay un edificio de tierra construido por el departamento de arquitectura con fines demostrativos: el pobre luce todo agrietado y a punto de caerse. Parece que la teoría falla a partir de cierta magnitud sísmica. Probablemente, también la nostalgia indigenista va a quedar afectada por este terremoto.

Al rato la radio empieza a informar del desastre en Las Colinas: media colonia sepultada por un enorme derrumbe; puede haber centenares de muertos. Casi simultáneamente vemos pasar helicópteros y suponemos que se dirigen hacia dicho sector. Después se sabrá de Comasagua, literalmente borrada del mapa. Lo mismo en otros pueblos, donde prácticamente no ha quedado piedra sobre piedra. Un lento goteo de noticias, a medida que se va sabiendo del interior del país. Hasta varios días más tarde irá mostrando la tragedia sus verdaderas, dramáticas, proporciones. Mucha gente en el área rural salvó la vida porque a esa hora no estaba en sus casas, o porque tuvieron tiempo de salir antes de que éstas se derrumbasen. San Agustín, por ejemplo, es un pueblo que prácticamente se desmoronó entero pero donde, según me cuenta Juan José, apenas se reportaron dos fallecidos. Si el terremoto hubiera sido en la madrugada el saldo total de víctimas mortales fuera de muchos miles. ¿Suerte dentro de la desgracia?

\section{Los siguientes días}

Sigue temblando bien seguido, a veces bastante fuerte. Hay vecinos que duermen en las cocheras, con los portones abiertos. Nosotros hemos puesto los colchones en la sala, a la par del dintel salvador que ya nos demostró su consistencia. Una fea grieta en el techo no parece tan preocupante, pero preferimos mirar hacia otro lado al acostarnos. No hay madrugada que no nos despertemos sobresaltados por la temblazón, varias veces cada noche; empieza a resultar desgastante. Al cuarto día hemos decidido "normalizarnos" y cada cual retoma su dormitorio respectivo, no sin antes desearnos las buenas noches con un fervor desacostumbrado. Si aguantó el terremoto, aguantará las réplicas - digo a mi familia, con tono convencido. Si lo que viene es otro peor, —pienso para mí mismo - tampoco nos daría tiempo de salir. Todo el mundo habla del terremoto y el tema se está volviendo obsesivo. A este paso, vamos a necesitar todos de terapia psicológica.

El país, al menos una tercera parte del mismo, está destruido. Ya se habla de un millón de damnificados. En los improvisados refugios hay miles de ellos. Hay lugares donde la gente sigue abandonada y desesperada. El tercernundismo imperante se refleja en la extrema lentitud con que fluye la ayuda, en la burocracia exasperan- 
te de las instancias oficiales, en la escasa capacidad de organización. El Canal 12, por ejemplo, muestra una cadena humana de voluntarios en sus instalaciones llenando un camión con ayuda de emergencia. Un grupo de jóvenes va pasándose los paquetes. ¿No sería más rápido y fácil retroceder el camión y acercarlo a la carga? Por todas partes prima la imagen de actividad frenética por encima de la verdadera eficacia. Es nuestro desastre cotidiano.

EI COEN, Comité de Emergencia Nacional, que ya había demostrado su inoperancia dos años antes, cuando las inundaciones provocadas por el huracán Mitch, parece decidido a superarse a sí mismo. Al gradc que ya hay quien irónicamente dice que sus siglas significan Comité de Estupidez Nacionalista. El comentario es desmesurado, pero refleja la indignación que ha despertado la ineptitud y el partidarismo. La política de embodegar la ayuda internacional, de suministrarla en cantidades mínimas y de canalizarla por medio de los gobemadores departamentales (dependientes del Ministerio del Interior) en lugar de los alcaldes, es otro desastre que se suma al del terremoto. Además, se dice que la Secretaría Nacional de la Familia ha entrado en competencia con el COEN por la distribución de la ayuda. Es decir, la Primera Dama de la Nación está rivalizando con el Ministro del Interior, dirigente de ARENA y uno de los "duros" del partido. Los políticos siguen jugando a la política, mientras los damnificados, con hambre y frío, durmiendo a la intemperie, siguen aguardando que la asistencia llegue.

Hay quien considera que la tragedia puede oxigenar políticamente al gobierno, acosado por la recesión económica y por las inquietudes que levanta su arriesgada apuesta por la dolarización del país. También hay quien afirma lo contrario, que el desastre acelerará su crisis. En la opinión de un reconocido analista mexicano, mucho va a depender de si el Presidente sabe encarar adecuadamente el reto. De momento lo que Francisco Flores ha encarado es el repudio de habitantes y familiares de Las Colinas, por haber llegado al lugar sin llevar medios de auxilio y por no haber atendido las protestas de los vecinos por la continuada urbanización de la Cordillera del Bálsamo. ¿Qué tanta responsabilidad tienen las empresas constructoras y el Estado en el derrumbe? ¿Han sido su acción y su omisión respectivas, causa del desastre? Probablemente no va a ser posible demostrarlo. Pero tampoco será posible demostrar lo contrario.

El Presidente parece decidido a limitar el papel del COEN y a impedir su confrontación con otras instancias guhemamentales; se anuncia la creación de una Comisión Nacional de Solidaridad encargada de la distribución. La preside un empresario cervecero, que es miembro del COENA — la dirigencia máxima de ARENA - y primer designado a la Presidencia. La Comisión más parece pensada para la imagen intemacional que para dar credibilidad en el nivel nacional. El obispo Rosa Chávez la califica de "una especie de COENA ampliado". El Presidente Flores parece acusar el golpe: replica que esa opinión es personal, que los únicos voceros oficiales de la Iglesia son el Nuncio Apostólico y el Arzobispo. Éste se ve

Como vueltos a nacer: Diario personal del ferremoto 
obligado a desmentirlo: el mencionado obispo es portavoz oficial, quien no lo es, es el Nuncio. Silencio presidencial después de esto.

Surge otra iniciativa de la empresa privada. Una Fundación presidida por una poderosa familia de hoteleros levanta una especie de "refugio de cinco estrellas". Alrededor de 600 personas, menos de 150 familias, son agraciadas con su traslado a este "albergue modelo", donde se alinean ordenadamente tiendas de campaña nuevas e inmaculadas. Tiene el aspecto de un tranquilo campamento de muchachos exploradores o de un grupo haciendo camping. ¿Será ésta la concepción que tienen los empresarios de lo que ha de ser un refugio de damnificados? Pero sirve para vender imagen de buena organización y eficacia. Cocineros y médicos de la Fuerza Armada colaboran en la atención que ahí se brinda, un equipo de psicólogos ofrece terapia post-traumática, mientras un grupo de educadores entretiene a los niños. Algunos periodistas afines al poder filman las escenas "modélicas". Sólo le falta proyección a futuro y un adecuado eslogan para este tipo de beneficencia: "Tenga la conciencia tranquila: ¡adopte un damnificado!"

Hay en El Salvador de hoy día mucho periodista crítico y capaz, en su mayoría jóvenes con sanas inquietudes por la responsabilidad de su profesión. En un reportaje realizado por uno de ellos se expone el caso de una señora en el refugio de El Cafetalón. Se trata de una pobre mendiga recogida por la policía cuando deambulaba por las calles, después de derrumbarse el edificio en cuya entrada solía pernoctar. "Yo, en realidad, — responde con total sinceridad al reporterono perdí nada, porque nada tenia. Aquí vivo con otras tres señoras en aquella tienda de campaña; nos dan comida tres veces al día y nos han regalado ropa." Me parece una joya periodística: haber encontrado alguien que sin quererlo se ha beneficiado con el desastre, que en su actual calidad de damnificada ha mejorado su situación. El caso no es tan insólito en este país, donde abundan los que podríamos llamar "damnificados permanentes".

Otros que se benefician con los desastres no son tan inocentes como la dama del citado reportaje. Varios clientes, indignados al comprobar que unas latas de aceite, de oferta en un supermercado, tenían la inscripción "donación del gobiemo de España", salieron a la calle a parar una patrulla de la policía y denunciar la presunta comercialización de la ayuda internacional a los damnificados. El encargado se vio obligado a "aclarar", ante la estupefacción de los denunciantes, la confusión: el aceite de oliva era una donación de cuando el Mitch, nada que ver con la ayuda por el terremoto. Pudo demostrar ante la policía, facturas en mano, que la cadena de tiendas (cuyo propietario ha sido un alto dirigente del partido gobemante) adquirió al Estado el lote de ayuda humanitaria para su comercialización. Todo bien legal; sin embargo, al siguiente día el aceite desaparecía discretamente de las estanterías del supermercado.

Con este tipo de anécdolas no es extraño que la mayoría de ONGs y varios gobiernos prefieran entregar sus donaciones directamente a los afectados, negán- 
dose a darla a los canales estatales. La amenaza de cobrar impuestos de importación a los envíos que no fueran entregados al COEN tuvo que dejarse sin efecto cuando algunas entidades de gran capacidad y prestigio rehusaron acatar esas disposiciones. Diversas instancias han focalizado en determinadas poblaciones su asistencia, generando así una especie de hermanamiento solidario. Varias de las zonas más devastadas están siendo atendidas mediante esta modalidad.

\section{Perspectivas}

"Es de sabios rectificar" afirma el dicho. A la semana del siniestro el gobiemo anuncia una nueva etapa en la cual, "para garantizar la rapidez" en la entrega de la ayuda, ésta se dará a los alcaldes para que sean ellos quienes la repartan entre los damnificados. Se va a proporcionar también una cantidad en efectivo a cada una de las familias afectadas, a cambio de que terminen de demoler y recojan el ripio de sus viviendas. Con toda pompa y frente a los medios de comunicación varios dignatarios estatales se desplazan hasta las zonas afectadas para hacer entrega oficial de la ayuda a los alcaldes respectivos. Podría parecer un cuento de hadas, después de la mala experiencia hecha con la centralización en la "primera etapa" (cuando mayor rapidez se hubiera requerido, dicho sea de paso).

"Ellos no son Santa Claus para andar repartiendo de esa forma", critica acremente el alcalde de Santa Tecla. Se ha roto el encantamiento inicial y buena parte de los alcaldes rehusa recibir el dinero: el gobierno está entregando solamente para una pequeña parte de los damnificados, después de haber anunciado con bombo y platillos que se le dará mil quinientos colones (unos 170 dólares) a cada familia damnificada. La gente anda detrás de los alcaldes para exigir la entrega del dinero pero éstos, o no lo han recibido, o lo que recibieron es poco y no alcanza sino para un mínimo porcentaje de la población afectada. Al parecer, tras las continuas protestas y manifestaciones frente a la sede del COEN, el gobierno ha decidido sacudirse esa "papa caliente" y pasarle a los alcaldes el problema de lidiar con las demandas populares. Pero los montos entregados están muy por debajo de las necesidades presentadas por las alcaldías en los censos locales de damnificados. La trampa política es muy obvia y levanta la protesta de la mayoría de los concejos municipales afectados, de todos los colores políticos, inclusive de ARENA.

El Presidente de COMURES, Corporación de Municipalidades de la República, Oscar Ortiz, alcalde de Santa Tecla por el FMLN, encabeza el liderazgo opositor ante la emergencia. Por gobernar uno de los municipios más afectados, haber sabido organizar rápidamente el mayor refugio del país (El Cafetalón) y haber coordinado acertadamente acciones de emergencia en su distrito, ha generado una positiva imagen de responsabilidad y de eficacia, que contrasta con la errática política gubernamental. Tiene también a su favor haber encabezado tiempo atrás las denuncias contra la urbanización de la Cordillera del Bálsamo, cuyo colap- 
so en el terremoto pareciera darle la razón. Para algunos incluso se proyecta como posible candidato del Frente en las elecciones presidenciales del 2004. Una combinación de los dos super-alcaldes del FMLN, Héctor Silva (ciudad capital) y Oscar Ortiz, se especula que podría arrastrar a buena parte de los votantes. "El guapo y el feo" sería esta posible fórmula, dado el buen predicado de que goza el primero entre el electorado femenino y el escaso atractivo físico del segundo. El gobierno parece estar consciente de dichos rumores y enfila baterías para desgastar a Oscar Ortiz. Las batallas políticas importantes están en el horizonte, a partir de la nueva agenda nacional que el terremoto ha impuesto a la nación.

$\mathrm{Ni}$ siquiera en el tema desastres naturales resulta ser competitivo el país. Un terremoto de similar magnitud en la India, acaecido a los pocos días, ha ocasionado 10 mil, 20 mil, o incluso tal vez 100 mil muertos, amén de una gran destrucción material. Es de prever que mucha ayuda internacional va ahora a repartirse entre las dos naciones, India y El Salvador, pues difícilmente gobiemos e instituciones vayan a duplicar sus presupuestos de asistencia humanitaria para atender ambas emergencias. Desgracia sobre desgracia, la casi simultaneidad de las dos tragedias af ecta doblemente a estas naciones. Resta sólo nuestra solidaridad humana con el sufrido pueblo hindú, cuya tragedia tiene un saldo de víctimas mortales pavoroso, aunque considerando el tamaño del país y de su población, El Salvador ha quedado af ectado en mucha mayor medida. Nuestras cifras reflejan que cerca de un $20 \%$ de la población y más de un $30 \%$ del territorio han sido dañados, por lo que los esfuerzos nacionales para revertir los efectos de la catástrofe serán a todas luces insuficientes sin una generosa y consistente ayuda internacional. Levantar nuevamente el país, dejando de lado intereses mezquinos y politiquería, es un ideal que suena poco realista dada nuestra historia y tradiciones, pero tal vez se pueda alcanzar una base de mínimos consensos para avanzar en la reconstrucción de este bello e intranquilo país.

San Salvador, 30 de enero de 2001. 